\title{
Evaluation of iron oxide nanoparticle biocompatibility
}

This article was published in the following Dove Press journal:

International Journal of Nanomedicine

I3 April 201 I

Number of times this article has been viewed

\author{
Amel Hanini $1,2,3,4,5$ \\ Alain Schmitt ${ }^{2,3,4}$ \\ Kamel Kacem ${ }^{5}$ \\ François Chau ${ }^{1,2}$ \\ Souad Ammar ${ }^{1,2}$ \\ Julie Gavard ${ }^{2,3,4}$ \\ Interface Traitement, Organisation \\ et Dynamique des Systèmes \\ (ITODYS), Université Paris 7, Paris, \\ France; ${ }^{2}$ CNRS, Paris, France; ${ }^{3}$ Inserm, \\ Paris, France; ${ }^{4}$ Univ Paris Descartes, \\ Paris, France; ${ }^{5}$ Universite de Carthage, \\ Jarzouna, Tunisia
}

Correspondence: Julie Gavard Institut Cochin, 22 Rue Mechain, Rm 306, 75014 Paris, France

$\mathrm{Tel}+33$ I 405। 6424

Fax +33 | 405 I 6430

Email julie.gavard@inserm.fr

\begin{abstract}
Nanotechnology is an exciting field of investigation for the development of new treatments for many human diseases. However, it is necessary to assess the biocompatibility of nanoparticles in vitro and in vivo before considering clinical applications. Our characterization of polyol-produced maghemite $\gamma-\mathrm{Fe}_{2} \mathrm{O}_{3}$ nanoparticles showed high structural quality. The particles showed a homogeneous spherical size around $10 \mathrm{~nm}$ and could form aggregates depending on the dispersion conditions. Such nanoparticles were efficiently taken up in vitro by human endothelial cells, which represent the first biological barrier to nanoparticles in vivo. However, $\gamma-\mathrm{Fe}_{2} \mathrm{O}_{3}$ can cause cell death within 24 hours of exposure, most likely through oxidative stress. Further in vivo exploration suggests that although $\gamma-\mathrm{Fe}_{2} \mathrm{O}_{3}$ nanoparticles are rapidly cleared through the urine, they can lead to toxicity in the liver, kidneys and lungs, while the brain and heart remain unaffected. In conclusion, $\gamma-\mathrm{Fe}_{2} \mathrm{O}_{3}$ could exhibit harmful properties and therefore surface coating, cellular targeting, and local exposure should be considered before developing clinical applications.
\end{abstract}

Keywords: nanoparticles, polyol process, endothelial cell, cytotoxicity, clearance

\section{Introduction}

Nanomaterial structures with dimensions between 1 and $100 \mathrm{~nm}$ are currently used for medical applications; such as magnetic drug targeting, hyperthermia, and enhanced resolution magnetic resonance imaging. ${ }^{1}$ Nanomedicine formulations aim at improving distribution and accumulation at the target sites. ${ }^{2}$ Hence, nanomaterials could improve the therapeutic index of low molecular weight drugs and provide more effective and less toxic treatment. ${ }^{3,4}$ However, levels of inorganic nanoparticles (NP) have already increased in ambient air and have impacted public health. ${ }^{1,2,5}$

Previous studies revealed that NP, such as iron oxide NP, can enter into cells and accumulate in mitochondria, vesicles, phagosomes and lysosomes. ${ }^{6-8}$ It has also been shown that coating of NP can efficiently improve internalization in many cell types. ${ }^{9}$ Toxic effects caused by iron oxide NP exposure remain controversial. Although the mechanism underlying NP-induced cytotoxicity is not completely understood, it could be related to inflammatory response and oxidative stress. ${ }^{6,10,11}$ While it has been shown that NP do not induce inflammatory reaction in vascular endothelial cells in vitro, they can significantly decrease cancer cell viability. ${ }^{7,8,12} \mathrm{NP}$ activity and toxicity depend not only on their chemical and structural properties but also on their size and surface properties. ${ }^{13,14}$ For instance, cell viability is enhanced by particle hydrodynamic size. ${ }^{15}$ However, little is known about the mechanisms involved in the potential adverse effects of NP, and their clinical development requires further evaluation of 
their biocompatibility. In this general context, we examined the cytotoxic effects of uncoated chemically-engineered iron oxide NP.

\section{Material and methods Iron oxide NP synthesis, characterization and labeling}

Maghemite $\gamma-\mathrm{Fe}_{2} \mathrm{O}_{3} \mathrm{NP}$ were engineered by a two-step method: magnetite $\mathrm{Fe}_{3} \mathrm{O}_{4}$ particles were first prepared by the polyol method using iron acetate salt as the precursor and diethyleneglycol as the solvent. ${ }^{16}$ Hot water was used to wash out the adsorbed organic residues on the NP surfaces and oxidize them to the maghemite form. The structure, size and shape of the particles produced were investigated by X-ray diffraction (PANalytical X'PertPro; PANalytical, Almelo, the Netherlands) and transmission electron microscopy (JEOL 100-CX II, 100 kV; JEOL, Tokyo, Japan). Their hydrodynamic mean size and surface charge were determined by a dynamic light scattering method (633 nm; Malvern Zetasizer; Nano, Malvern, UK) in deionized water, $\mathrm{MgCl}_{2}$ - and $\mathrm{CaCl}_{2}$-free phosphate saline buffer (PBS) pH 7.2, Dulbecco's Modified Eagle Medium (DMEM; Invitrogen, Carlsbad, CA) and $\mathrm{NaCl}$ $0.9 \%$ solution. $\gamma-\mathrm{Fe}_{2} \mathrm{O}_{3} \mathrm{NP}$ were functionalized with 3,4-dihydroxyphenylethylamine hydrochloride where the amine function serves to attach fluorescein isothiocyanate (FITC) chromophore. The functionalized $\gamma-\mathrm{Fe}_{2} \mathrm{O}_{3} \mathrm{NP}$ ( $1 \mathrm{mg} / \mathrm{mL}$ in PBS) was mixed with $10 \mathrm{mg} / \mathrm{mL}$ of FITC dissolved in $\mathrm{NaHCO}_{3} / \mathrm{Na}_{2} \mathrm{CO}_{3} 1 \mathrm{M}$ overnight. Labeled NP were eluted with PBS and filtered through a $0.22 \mu \mathrm{m}$ membrane. Labeling did not affect $\gamma-\mathrm{Fe}_{2} \mathrm{O}_{3} \mathrm{NP}$ properties, as estimated by dynamic light scattering.

\section{Cell culture}

Immortalized human umbilical vascular endothelial cells (HUVEC, Ea.hy 926 clone $^{17}$ ) were maintained in DMEM plus $10 \%$ fetal bovine serum and $1 \%$ penicillin/streptomycin (Invitrogen).

\section{Confocal and electron microscopy}

Cells were seeded on glass coverslips 24 hours prior to treatment with $10 \mu \mathrm{g} / \mathrm{mL}$ of FITC-labeled $\gamma-\mathrm{Fe}_{2} \mathrm{O}_{3} \mathrm{NP}$ for indicated times. Fixed samples (4\% paraformaldehyde/PBS, 15 minutes) were mounted in 4,6-diaminidino-2-phenylindole (DAPI)-containing mounting medium (Vector Laboratories, Burlingame, CA). Images were captured using a Leica SP2 confocal microscope (Leica Microsystems GmbH, Wetzlar, Germany; Imagery facility, Institut Cochin).
Cells were seeded on glass coverslips 24 hours prior to treatment with $10 \mu \mathrm{g} / \mathrm{mL}$ of $\gamma-\mathrm{Fe}_{2} \mathrm{O}_{3} \mathrm{NP}$ for indicated times, then prepared for electron microscopy (3\% glutaraldehyde/ PBS, 1 hour). After incubation in $1 \% \mathrm{OsO}_{4}$, cells were dehydrated in graded dilutions of ethanol, embedded in artificial resin (Epon; Momentive Specialty Chemicals, Colombus, $\mathrm{OH}$ ) and processed for electron microscopy. Subcellular localization of NP was monitored by transmission electron microscopy (EM10CR; Zeiss, Oberkochen, Germany; Imagery facility, Institut Cochin) performed at $60-80 \mathrm{kV}$ on unstained thin sections.

\section{Western blot}

Proteins were collected in TNT buffer (10 mM Tris$\mathrm{HCl}$ pH 7.5, 150 mM NaCl, 1\% Triton X100, 2 mM EDTA) plus protease inhibitors (Sigma-Aldrich, St Louis, MO), $200 \mathrm{mM} \mathrm{NaF}$ and $0.1 \mathrm{mM} \mathrm{Na3VO}$. Equal amounts of proteins (Pierce microBCA kit; Thermo Scientific, Pittsburg, PA) were separated with 4\%-12\% Nupage gels (Invitrogen) and transferred onto polyvinylidene fluoride (PVDF) membranes (Thermo Scientific). Primary anti-phospho-Akt, Akt, phospho-eNOS (endothelial nitric oxide synthase), eNOS, and Caspase 3 antibodies were used (Cell Signaling Technology, Beverly, MA). Alexa 680-conjugated secondary antibodies (Invitrogen) were used and membranes were scanned using the Odyssey infrared imaging system (Li-Cor Biosciences GmbH, Bad Homburg vor der Höhe, Germany).

\section{Cell viability, toxicity and intracellular reactive oxygen species assays}

Five thousand HUVEC were cultured overnight onto 96-well plates. After sonication in serum-free DMEM, freshly produced $\gamma-\mathrm{Fe}_{2} \mathrm{O}_{3} \mathrm{NP}$ were added at increasing concentrations at the indicated times. Cell viability was assessed using the 3-(4,5-dimethylthiazol-2-yl)diphenyltetrazolium bromide (MTT) method according to manufacturer's instructions (SigmaAldrich) as previously reported. ${ }^{18}$ Cell viability was calculated as a ratio between treated (sample) and untreated (control).

Toxicity was measured using the lactate dehydrogenase (LDH) detection kit according to manufacturer's instructions (Roche, Basel, Switzerland) on cell culture supernatant and cell lysates recovered in 2\% Triton-X100. Optical density (OD) was measured at $492 \mathrm{~nm}$ with a standard microplate reader (Multiskan Ex; Thermo Scientific). LDH leakage was calculated using the following equation: [Supernatant OD/(Supernatant OD + Lysate OD) × 100].

Forty thousand HUVEC were cultured in 96-well plate format. At designated times, cells were washed and 
incubated with Hank's Buffered Salt Solution (HBSS) containing 2', 7'-dichlorofluorescin diacetate (DCFH-DA, $20 \mu \mathrm{M}$, Sigma) for 30 minutes. Fluorescence was read at $485 \mathrm{~nm} \mathrm{Ex/530} \mathrm{nm} \mathrm{Em} \mathrm{(Fusion).} \mathrm{Values} \mathrm{were} \mathrm{normalized}$ to their respective controls.

\section{In vivo studies}

Rats were cared for under the Tunisian Code of Practice for the Care and Use of Animals for Scientific purposes, and experimental protocols were approved by the Ethics Committee of the Faculte des Sciences de Bizerte (Tunisia). Wistar rats weighing 100-150 g (Institut Pasteur, Tunisia) were randomly divided into experimental and control groups. Rats received either $\gamma-\mathrm{Fe}_{2} \mathrm{O}_{3} \mathrm{NP}(0.8 \mathrm{mg} / \mathrm{kg})$ by single intravenous injection for the experimental group or saline solution $(\mathrm{NaCl}$ $0.9 \%$ ) for the control group. Animal weight was monitored during the course of the experiment. Two weeks later, rats were sacrificed and blood samples and organs were collected. For histological analysis, $4 \mu \mathrm{m}$-thick sections of paraffinembedded organs were stained with hematoxylin and eosin. A sample of $0.5 \mathrm{~mL}$ of blood was collected from each animal at the end of the experiment. White and red blood cells were counted (Medonic Blood Cell Analyzer CA 620; Medonic, Walpole, MA).

For clearance analysis, $0.3 \mathrm{mg} / \mathrm{mL}$ FITC-labeled $\gamma-\mathrm{Fe}_{2} \mathrm{O}_{3} \mathrm{NP}$ was injected into the tail vein. Blood and urine were collected at the indicated times. Fluorescence was quantified by fluorimeter (VARIAN Cary Eclipse, Ex485 nm/Em500-590 nm; Agilent Technologies, Palo Alto, CA) and flow cytometry (FACS Coulter Epics XL, EXPO32 software; Applied Cytometry Systems, Sacramento, CA).

\section{Statistical analysis}

All experiments were carried out in triplicate and six animals were used per group. Data were analyzed using one-way analysis of variance (ANOVA) followed by unpaired Student's $t$-test (Prism, GraphPad Software, Inc, La Jolla, CA). Values are expressed as mean \pm standard deviation (SD). $P$-values of $<0.05$ were considered statistically significant.

\section{Results}

\section{Iron oxide NP characterization}

The powder recovered by centrifugation corresponds to the $\gamma-\mathrm{Fe}_{2} \mathrm{O}_{4}$ phase which crystallizes in the cubic spinel structure (Figure 1A) with a cell parameter $(\mathrm{a}=8.36 \AA)$ close to that of bulk maghemite $(\mathrm{a}=8.3515 \AA) .{ }^{20}$ Potentiometric titration, using potassium permanganate solution, after dissolution of an appropriate amount of powder in concentrated sulfuric acid, established that the iron species are exclusively ferric ions, in agreement with the formation of the maghemite phase. To determine the morphology and the mean size of the as-produced maghemite particles, low- and high-resolution transmission electron microscopy was performed. Pictures show that $\gamma-\mathrm{Fe}_{2} \mathrm{O}_{3} \mathrm{NP}$ were mainly uniform in size with a $10 \mathrm{~nm} \pm 20 \%$ diameter on average and with a spherical shape (Figure 1B). These results are in agreement with the average crystal size inferred from X-ray diffraction line broadening using the Scherrer formula. ${ }^{16,18}$ There is no evidence of physical defects such as dislocation and stacking, or of amorphous regions at the surface, suggesting high crystalline quality in single particles.

Hydrodynamic diameter and zeta potential dispersed in distilled water, PBS, DMEM and saline solution after ultrasonication are given in Table 1 . The measured hydrodynamic sizes appeared larger than when evaluated by electron microscopy, probably because magnetic dipole-dipole interactions between $10 \mathrm{~nm}$ sized crystals can provoke $\gamma-\mathrm{Fe}_{2} \mathrm{O}_{3}$ NP aggregation. This aggregation can reach micrometersize ranges in water, where surface charges are positive. In contrast, they are negative in $\mathrm{PBS}, \mathrm{NaCl} 0.9 \%$ and DMEM.

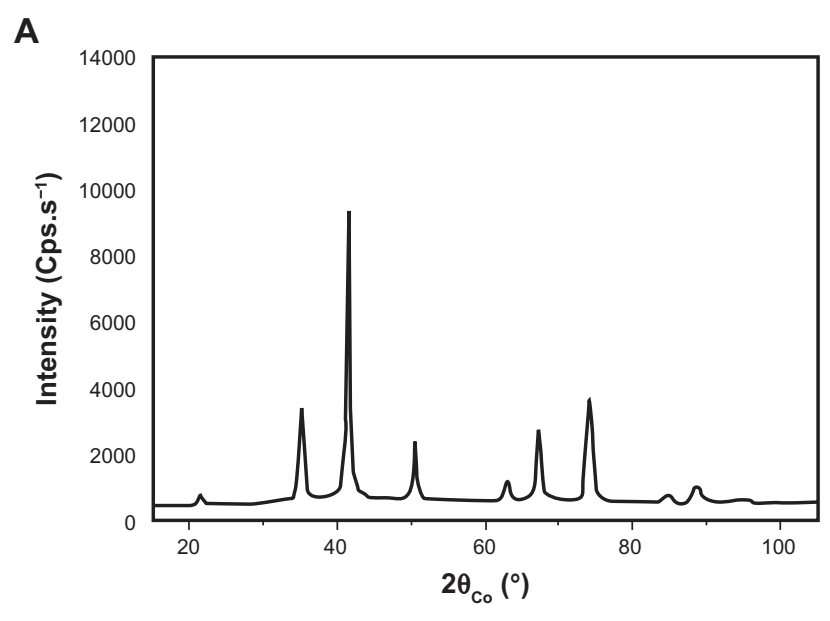

B
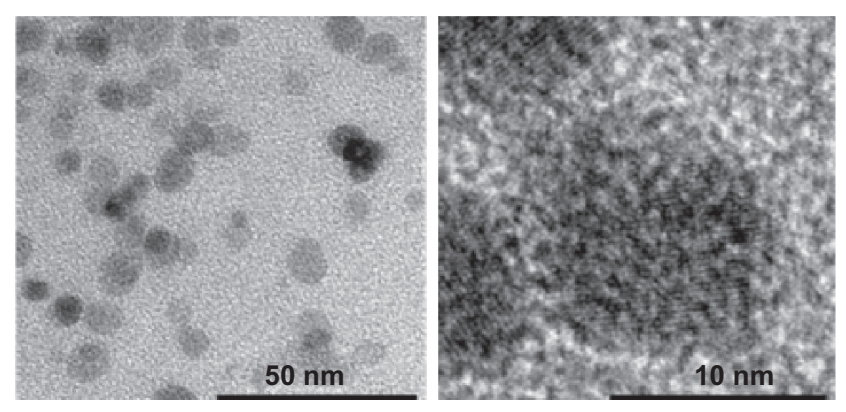

Figure I Nanoparticles exhibit spherical shapes. A) Polyol-made iron oxide powder consists of maghemite nanocrystals as shown by their broadened $X$-ray diffraction pattern. B) $\mathrm{Fe}_{2} \mathrm{O}_{3}$ iron oxide nanoparticle morphology was observed by transmission electron microscopy on a collection of as-produced particles (left image). A zoom on one representative particle is shown (right panel). 
Table I Physical properties of iron oxide nanoparticle

\begin{tabular}{lllll}
\hline Solution & $\begin{array}{l}<\mathbf{D}_{\text {DLs }}> \\
(\mathbf{n m})\end{array}$ & $\begin{array}{l}\text { Zeta } \\
\text { potential } \\
(\mathbf{m v})\end{array}$ & $\begin{array}{l}\text { Conductivity } \\
(\mathbf{m s} / \mathbf{c m})\end{array}$ & $\begin{array}{l}\text { Effective } \\
\text { voltage } \\
(\mathbf{V})\end{array}$ \\
\hline $\begin{array}{l}\text { Distilled } \\
\text { water }\end{array}$ & 2420 & +12.8 & - & - \\
$\begin{array}{l}\text { PBS } \\
\text { solution }\end{array}$ & 204 & -23.6 & 15.7 & 49.5 \\
$\begin{array}{l}\text { DMEM } \\
\begin{array}{l}\text { Saline } \\
\text { solution }\end{array}\end{array}$ & 90 & -9.1 & 14.3 & 49.5 \\
\hline
\end{tabular}

Notes: Average hydrodynamic diameter (DLS), zeta potential, electric conductivity and voltage of produced iron oxide particles were measured when dispersed in distilled water, PBS and DMEM liquids.

These physicochemical properties might help to explain the potential interactions between $\gamma-\mathrm{Fe}_{2} \mathrm{O}_{3} \mathrm{NP}$ and the biological environment.

\section{Internalization of iron oxide NP}

The endothelium may represent the first biological barrier to $\mathrm{NP}$ when used in vivo. We initially examined the interactions between human endothelial cells and $\gamma-\mathrm{Fe}_{2} \mathrm{O}_{3}$ NP by confocal microscopy. FITC-labelled $\gamma-\mathrm{Fe}_{2} \mathrm{O}_{3} \mathrm{NP}$ were incubated with HUVEC monolayers. This analysis clearly showed that $\gamma-\mathrm{Fe}_{2} \mathrm{O}_{3} \mathrm{NP}$ could be internalized in HUVEC and most of the fluorescence borne by $\gamma-\mathrm{Fe}_{2} \mathrm{O}_{3} \mathrm{NP}$ seems to localize within the cytoplasm (Figure 2). Electron microscopy showed that $\gamma-\mathrm{Fe}_{2} \mathrm{O}_{3} \mathrm{NP}$ are found outside the cell periphery in the short term, but can efficiently reach internal structures within a few hours (Figure 3). Interestingly, aggregate features of $\gamma-\mathrm{Fe}_{2} \mathrm{O}_{3}$ $\mathrm{NP}$ were observed both freely diffused in the cytoplasm and trapped in single membrane organelles (Figure 3). They were however not detected in the nucleus even after 48 hours of incubation. Interestingly, $\gamma-\mathrm{Fe}_{2} \mathrm{O}_{3} \mathrm{NP}$ could penetrate cells without any protein-coated vesicles, suggesting a micropinocytotic process.

\section{Iron oxide NP alter endothelial viability}

In order to assess biocompatibility, we investigated whether $\gamma-\mathrm{Fe}_{2} \mathrm{O}_{3} \mathrm{NP}$ could alter the endothelial biology once they had entered the cells. We performed MTT assays that measured the mitochondrial activity and therefore reflected the number of viable cells. We found that $\gamma-\mathrm{Fe}_{2} \mathrm{O}_{3} \mathrm{NP}$ had no significant effect on HUVEC viability up to 24 hours after exposure, but a severe drop-off was revealed after 48 hours and persisted at 72 hours (Figure 4A). Strikingly, no dose effects were detected, even at concentrations as low as $0.1 \mathrm{mg} / \mathrm{mL}$. We checked these results by measuring the cell toxicity of $\gamma-\mathrm{Fe}_{2} \mathrm{O}_{3}$ NP. Cell death was monitored by the

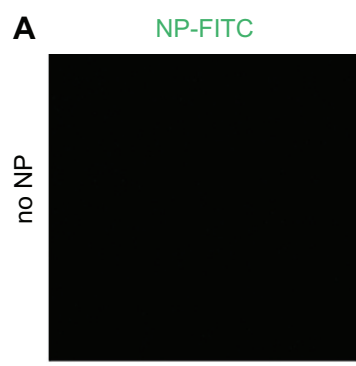

NP-FITC + DAPI
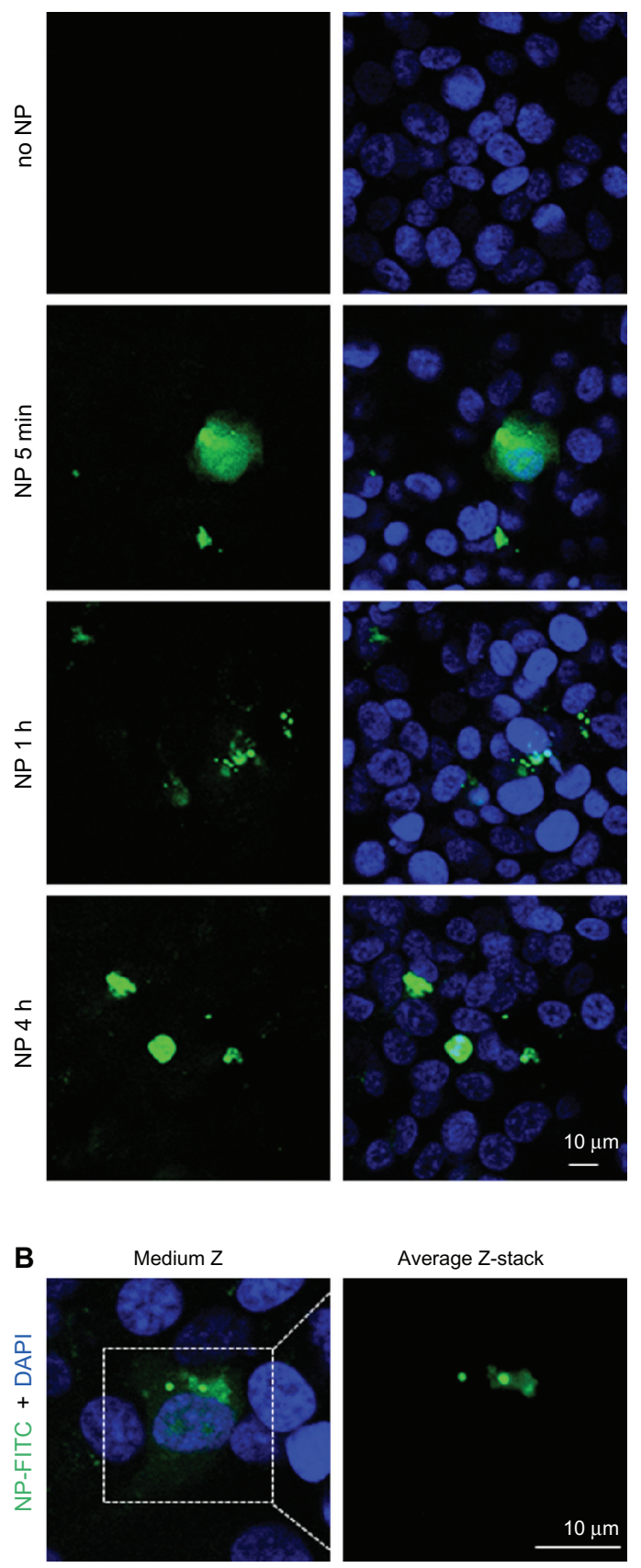

Average Z-stack

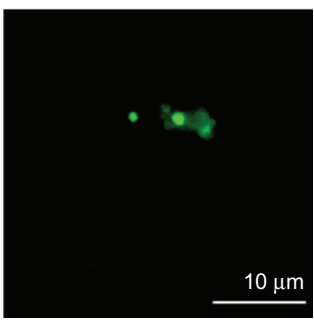

Figure 2 Nanoparticle internalization in human endothelial cells. A and B) Human umbilical vein endothelial cells (HUVEC) were incubated with FITC-labelled nanoparticle (NP, $10 \mu \mathrm{g} / \mathrm{mL}$, green) for the indicated times in serum-free medium. Nuclei were counterstained with 4,6-diamidino-2-phenylindole (DAPI) (blue) and samples were analyzed by confocal microscopy.

so-called LDH leakage assay. This stable cytosolic enzyme can leak into the extracellular fluid after membrane damage occurring during necrosis. Toxicity markedly increased after 24 hours of contact with $\gamma-\mathrm{Fe}_{2} \mathrm{O}_{3} \mathrm{NP}$ (Figure 4B), corroborating the results obtained with MTT. Furthermore, phosphorylation of Akt, a pro-survival protein was decreased on $\gamma-\mathrm{Fe}_{2} \mathrm{O}_{3} \mathrm{NP}$ exposure, while caspase 3 cleavage, a sign of 


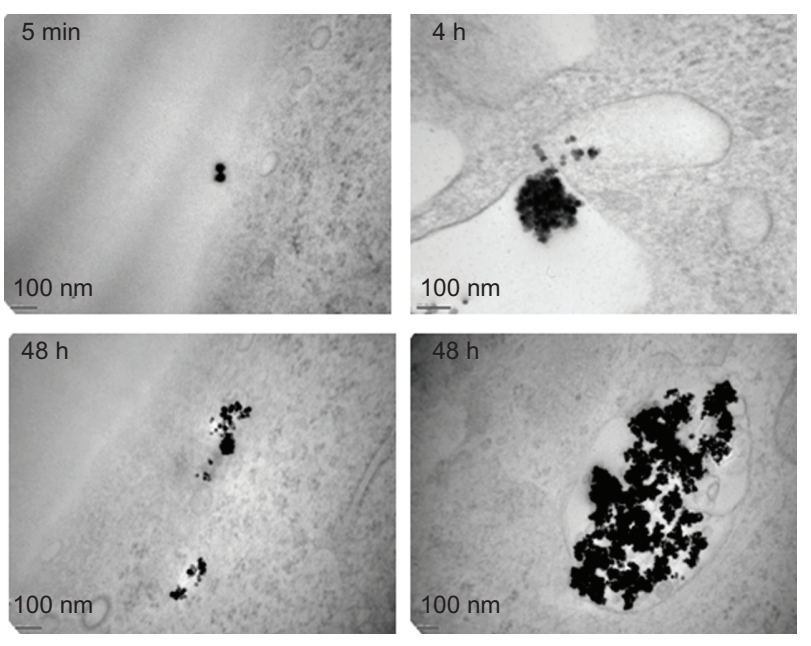

Figure 3 Subcellular localization of nanoparticles. Transmission electron microscopy was performed on human umbilical vascular endothelial cells (HUVEC) exposed to nanoparticles for the indicated times.

apoptosis, was not observed (Figure 4C). Hence, our results suggest that $\gamma-\mathrm{Fe}_{2} \mathrm{O}_{3} \mathrm{NP}$ can induce long-term toxicity in human endothelial cells by a necrotic process. Interestingly, endothelial nitric oxide synthase (eNOS) seems to be transiently phosphorylated in cells exposed to $\gamma-\mathrm{Fe}_{2} \mathrm{O}_{3} \mathrm{NP}$ (Figure 4C). To further evaluate whether eNOS activation was accompanied by an increase in oxidative stress, reactive oxygen species (ROS) production was monitored. As shown in Figure 4D, relative ROS quantity was slightly but significantly enhanced in $\gamma-\mathrm{Fe}_{2} \mathrm{O}_{3} \mathrm{NP}$-stimulated HUVEC after 24 hours. Thus, cell death and ROS production both peak at 24 hours postexposure to $\gamma-\mathrm{Fe}_{2} \mathrm{O}_{3} \mathrm{NP}$. Our results suggest that $\gamma-\mathrm{Fe}_{2} \mathrm{O}_{3} \mathrm{NP}$ can promote cell death after 24 hours of exposure, most likely through oxidative stress and necrosis mechanisms.

\section{In vivo toxicity of iron oxide NP}

Because in vitro toxicity was observed after 24 hours, we decided to explore the effects of $\gamma-\mathrm{Fe}_{2} \mathrm{O}_{3} \mathrm{NP}$ exposure in vivo. Clearance of injected FITC-labeled $\gamma-\mathrm{Fe}_{2} \mathrm{O}_{3} \mathrm{NP}$ was estimated, compared to background fluorescence in controls (Figure 5A). Blood analysis showed that $40 \%$ of injected $\gamma-\mathrm{Fe}_{2} \mathrm{O}_{3} \mathrm{NP}$ were removed from systemic circulation after 24 hours and that $75 \%$ were eliminated after 72 hours (Figure 5A and B). A large quantity was cleared in the urine (Figure 5A and B). Animal weight was monitored during the course of the experiments. The graph presented in Figure 5C illustrates the fact that $\gamma-\mathrm{Fe}_{2} \mathrm{O}_{3} \mathrm{NP}$ did not alter the general health of the animals. In addition, no signs of distress, such as loss of hair or behavioral changes were observed. However, the number of white blood cells was augmented by about $50 \%$ in $\gamma-\mathrm{Fe}_{2} \mathrm{O}_{3} \mathrm{NP}$-injected animals, while red blood cell counts remained unaffected (Figure 5D). This prompted us to investigate the histology of the main organs for any sign of immunological reactions. Inflammation as indicated by eosin-positive infiltrated cells was detected in lungs, liver and kidney (Figure 4E, squares). Heart and brain structures do not appear to be modified in NP-injected animals.

We concluded that $\gamma-\mathrm{Fe}_{2} \mathrm{O}_{3} \mathrm{NP}$ are efficiently taken up by endothelial cells where they produce toxic effects after 24 hours. When injected in vivo, such NP can promote cellular damage in the liver, kidney and lungs, although they are rapidly cleared. Clinical applications require improvement of NP biocompatibility.

\section{Discussion}

Our work was designed to determine whether $10 \mathrm{~nm}$-sized iron oxide $\mathrm{NP}\left(\gamma-\mathrm{Fe}_{2} \mathrm{O}_{3} \mathrm{NP}\right)$ are biocompatible with clinical use, especially local hyperthermia application in solid tumors. We first aimed at understanding whether $\gamma-\mathrm{Fe}_{2} \mathrm{O}_{3}$ NP could penetrate the endothelium without causing any potential toxicity, using in vitro human endothelial cells (HUVEC) and an in vivo rat model. We found that $\gamma-\mathrm{Fe}_{2} \mathrm{O}_{3}$ NP are internalized in HUVEC quite efficiently within a few hours, but can provoke cell death 24 hours postexposure, most likely through the oxidative stress pathway. Although $\gamma-\mathrm{Fe}_{2} \mathrm{O}_{3} \mathrm{NP}$ are eliminated through urine when injected in vivo, they could induce toxicity in some organs while sparing the brain and heart. Our study suggests that $\gamma-\mathrm{Fe}_{2} \mathrm{O}_{3} \mathrm{NP}$ could be used in vivo for very short times but they may need further improvement to reduce their toxicity and to increase their targeted delivery.

Particles used here correspond to the maghemite phase and are free from any coating. DLS measurements have shown that the particles tend to aggregate when dispersed in hydrophilic solutions. This was also confirmed by electron microscopy analysis. This property may affect their biological action; for example, increased toxicity was correlated with carbon nanotube aggregation. ${ }^{19}$ In addition, it has been suggested that cellular uptake may be modulated by aggregation state. ${ }^{3}$ Experiments demonstrated that $\gamma-\mathrm{Fe}_{2} \mathrm{O}_{3} \mathrm{NP}$ are internalized either in the cytosol or in membrane-delimited vesicles.

Evaluation of cell toxicity by different means suggest a long-term toxic effect of $\gamma-\mathrm{Fe}_{2} \mathrm{O}_{3} \mathrm{NP}$ in human endothelial cells. No dose-dependent action of $\gamma-\mathrm{Fe}_{2} \mathrm{O}_{3} \mathrm{NP}$ was detected. Our results point to a correlation between exposure time and cell toxicity. Molecular mechanisms involved in 


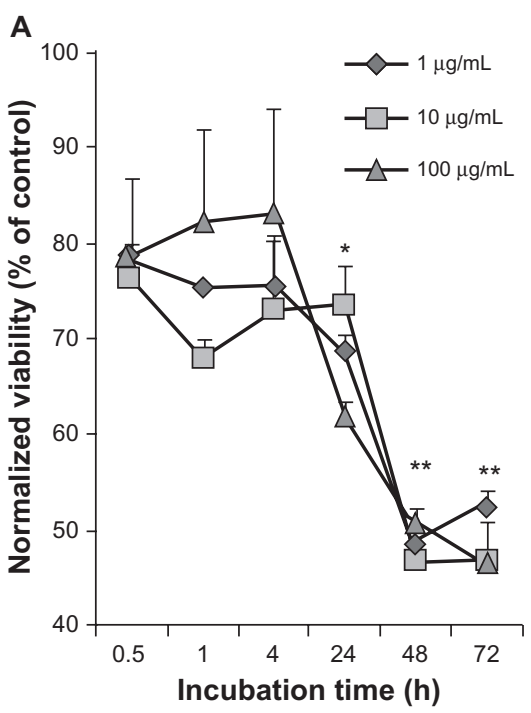

C

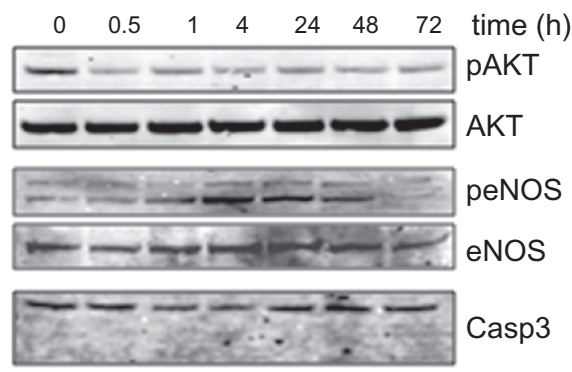

B

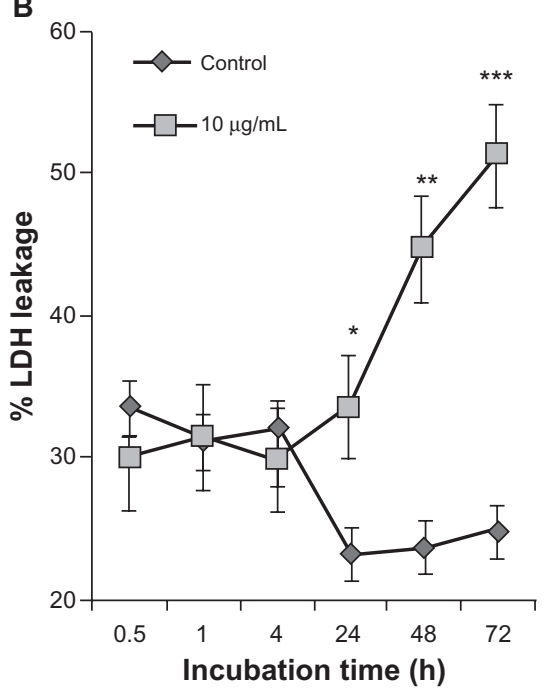

D

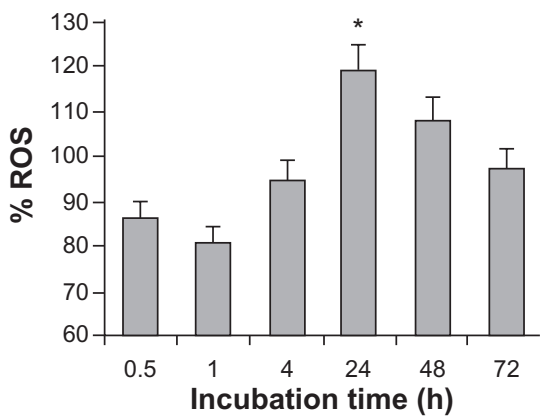

Figure 4 Effect of nanoparticles on endothelial cell viability. A) The number of viable cells was measured by 3-(4,5-dimethylthiazol-2-yl) diphenyltetrazolium bromide (MTT) when exposed to nanoparticles (NP) at the indicated times and concentrations. Results were expressed as a ratio to nonstimulated serum-free cultured cells for each time point. B) Cell toxicity was evaluated by LDH leakage and calculated as described in the method section, in human umbilical vein endothelial cells (HUVEC) exposed to $10 \mu \mathrm{g} / \mathrm{mL}$ of NP. C) Cells exposed to $10 \mu \mathrm{g} / \mathrm{mL}$ of NP were harvested for Western blot analysis at the indicated time points. Phosphorylation (P) of Akt and endothelial nitric oxide synthase (eNOS) was monitored, along with Akt, eNOS and Caspase 3. D) Reactive oxygen species (ROS) production was examined in NP (I0 $\mu$ g/mL)-exposed HUVEC at the indicated time points. Fluorescence values were normalized to the ones obtained in control conditions.

Notes: All results are representative of three independent experiments, ${ }^{*} * P<0.01$; $* P<0.05$.

$\gamma$ - $\mathrm{Fe}_{2} \mathrm{O}_{3} \mathrm{NP}$-mediated cell death may rely on oxidative stress occurring after 24 hours. NP-decreased cell viability kinetics are significantly slower than canonical death inducers, such as staurosporine. The mechanism involved here is rather complex, as it requires NP entrance and interference with oxidative stress pathways.

To examine in vivo effects, $\gamma-\mathrm{Fe}_{2} \mathrm{O}_{3} \mathrm{NP}$ were administered by single intravenous injection to allow maximum bioavailability. Their persistence and their proportional distribution depend on their size. ${ }^{3}$ Aggregation of particles, evidenced by DLS measurement in saline solution, may decrease when in the blood stream, because of its molecular and cellular composition and viscosity, suggesting that smaller clusters could form and cross the endothelial barrier. This was confirmed by in vitro experiments. Iron oxide NP led to cytopathological effects in lungs, liver and kidneys following systemic administration. The perivascular inflammation indicates that $\gamma-\mathrm{Fe}_{2} \mathrm{O}_{3} \mathrm{NP}$ could reach several organs such as the lungs and kidneys. Correlating with this, we also found an increase in white blood cell numbers, suggesting an inflammatory process. In contrast, the red blood cell number remained unchanged, indicating low toxicity of these particles towards erythrocytes. The brain may be protected by the blood-brain barrier, which is selective to particles larger than $1 \mathrm{~nm}$. We did not observe any toxicity of $\gamma-\mathrm{Fe}_{2} \mathrm{O}_{3} \mathrm{NP}$ when applied in vitro to human brain endothelial cells. Absorption of $\gamma-\mathrm{Fe}_{2} \mathrm{O}_{3}$ $\mathrm{NP}$ in lungs, liver and kidneys may be most likely related to their specific vascularization and vessel permeability. Our data suggest that despite rapid clearance, polyol-made maghemite $10 \mathrm{~nm}$ diameter particles induced in vitro and in vivo cytotoxicity after prolonged exposure. $\gamma-\mathrm{Fe}_{2} \mathrm{O}_{3} \mathrm{NP}$ 
A

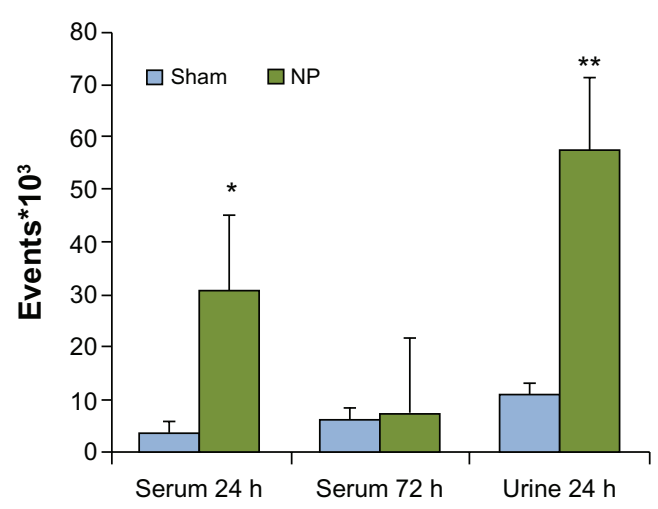

C

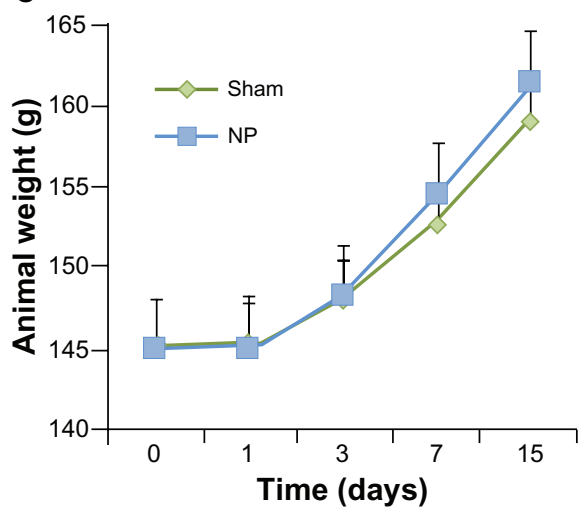

D

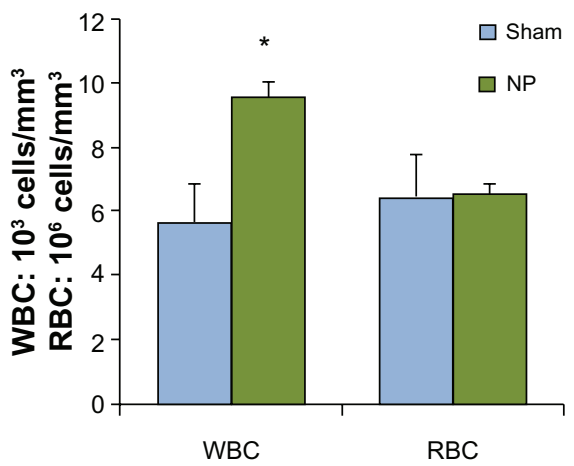

B

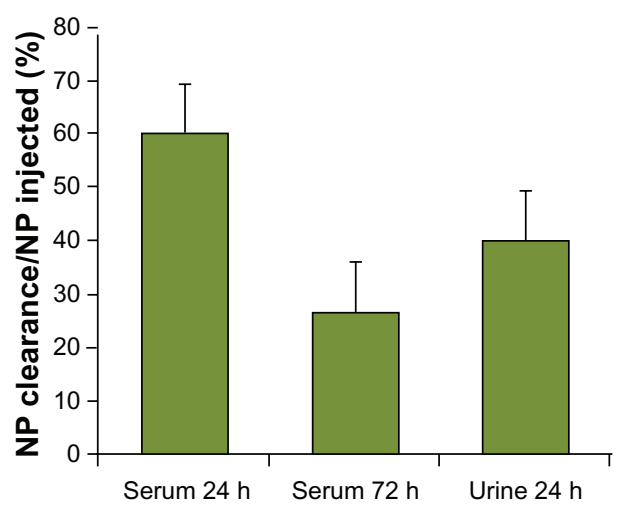

E

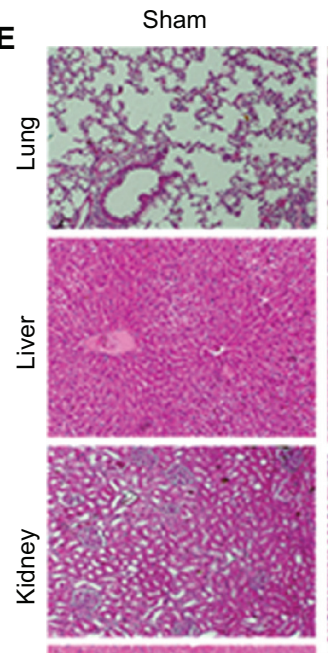

$\mathrm{NP}$
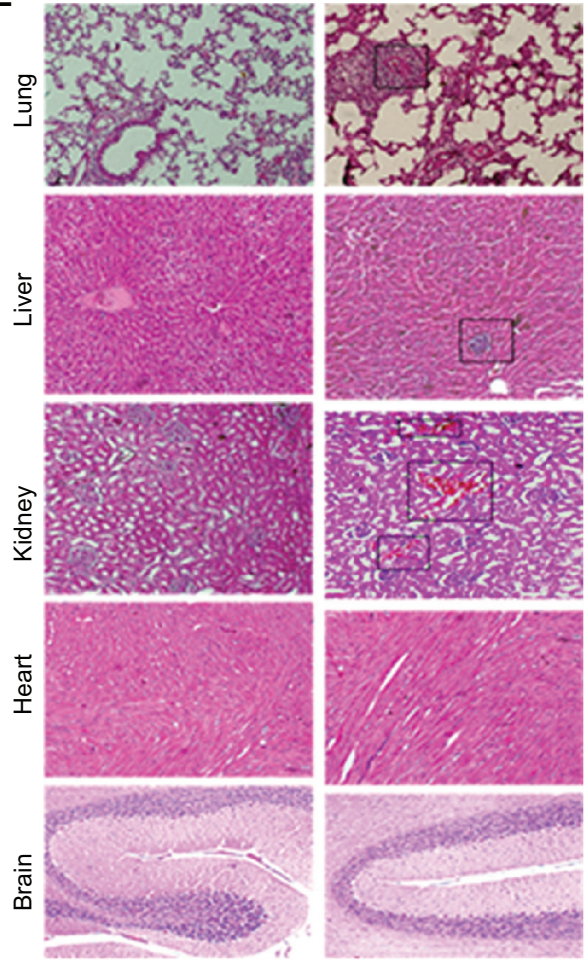

Figure 5 In vivo clearance and toxicity of nanoparticles. Six animals for each groups received saline (Sham) or nanoparticle (NP) (0.8 mg/kg NP) by intravenous injection. A and B) Blood and urine clearance profile of fluorescein isothiocyanate (FITC)-labeled NP was measured either by flow cytometry or spectrophotometry, respectively, after 24 and 72 hours. C) Animals were weighed during the course of control and NP treatment. D) Numbers of white and red blood cells (WBC, RBC) were examined in animals treated with control and NP for 14 days. E) Organs were collected 14 days post-treatment and processed for staining with hematoxylin and eosin.

Notes: $* * P<0.01 ; * P<0.05$

could induce adverse effects and therefore surface coating, cellular targeting, and local exposure should be considered before clinical applications are developed.

\section{Acknowledgments}

The authors are indebted to Dr F Herbst and Dr M Hamadi for their assistance in electron microscopy analysis and chemical NP surface modification. This research was supported by a grant from Ligue Nationale contre le Cancer, comite de Paris, the $C M C U$ France-Tunisia Cooperation Research Program and Association pour la Recherche sur le Cancer. $\mathrm{AH}$ is supported by a $\mathrm{PhD}$ fellowship from the Ministere des Affaires Etrangeres, Bourse d'Excellence Eiffel.

\section{Disclosure}

The authors report no conflicts of interest in this work. 


\section{References}

1. Maynard AD, Aitken RJ, Butz T, et al. Safe handling of nanotechnology. Nature. 2006;444:267-269.

2. Lanone S, Boczkowski J. Biomedical applications and potential health risks of nanomaterials: molecular mechanisms. Curr Mol Med. 2006;6:651-663.

3. Hall JB, Dobrovolskaia MA, Patri AK, McNeil SE. Characterization of nanoparticles for therapeutics. Nanomedicine (Lond). 2007;2: 789-803.

4. Lammers T, Kiessling F, Hennink WE, Storm G. Nanotheranostics and image-guided drug delivery: Current concepts and future directions. Mol Pharm. 2010;7:1899-1912.

5. Colvin VL. The potential environmental impact of engineered nanomaterials. Nat Biotechnol. 2003;21:1166-1170.

6. Xia T, Kovochich M, Brant J, et al. Comparison of the abilities of ambient and manufactured nanoparticles to induce cellular toxicity according to an oxidative stress paradigm. Nano Lett. 2006;6:1794-1807.

7. Gojova A, Guo B, Kota RS, Rutledge JC, Kennedy IM, Barakat AI. Induction of inflammation in vascular endothelial cells by metal oxide nanoparticles: effect of particle composition. Environ Health Perspect. 2007;115:403-409.

8. Kirchner C, Liedl T, Kudera S, et al. Cytotoxicity of colloidal CdSe and CdSe/ZnS nanoparticles. Nano Lett. 2005;5:331-338.

9. Bhirde AA, Patel V, Gavard J, et al. Targeted killing of cancer cells in vivo and in vitro with EGF-directed carbon nanotube-based drug delivery. ACS Nano. 2009;3:307-316.

10. Hussain SM, Hess KL, Gearhart JM, Geiss KT, Schlager JJ. In vitro toxicity of nanoparticles in BRL 3A rat liver cells. Toxicol In Vitro. 2005;19:975-983.

11. Braydich-Stolle, Hussain S, Schlager JJ, Hofmann MC. In vitro cytotoxicity of nanoparticles in mammalian germline stem cells. Toxicol Sci. 2005;88:412-419.
12. Dobrovolskaia MA, McNeil SE. Immunological properties of engineered nanomaterials. Nat Nanotechnol. 2007;2:469-478.

13. Warheit DB, Webb TR, Reed KL, Frerichs S, Sayes CM. Pulmonary toxicity study in rats with three forms of ultrafine-TiO2 particles: differential responses related to surface properties. Toxicology. 2007; 230:90-104.

14. Nel A, Xia T, Madler L, Li N. Toxic potential of materials at the nanolevel. Science. 2006;311:622-627.

15. Mahmoudi M, Simchi A, Imani M, Milani AS, Stroeve P. An in vitro study of bare and poly(ethylene glycol)-co-fumarate-coated superparamagnetic iron oxide nanoparticles: a new toxicity identification procedure. Nanotechnology. 2009;20:225104.

16. Basti H, Ben Tahar L, Smiri LS, et al. Catechol derivatives-coated $\mathrm{Fe} 3 \mathrm{O} 4$ and gamma-Fe2O3 nanoparticles as potential MRI contrast agents. J Colloid Interface Sci. 2010;341:248-254.

17. Edgell CJ, McDonald CC, Graham JB. Permanent cell line expressing human factor VIII-related antigen established by hybridization. Proc Natl Acad Sci U S A. 1983;80:3734-3737.

18. Beji Z, Hanini A, Smiri LS, et al. Magnetic properties of Zn-substituted $\mathrm{MnFe} 2 \mathrm{O} 4$ nanoparticles synthesized in polyol as potential heating agents for hyperthermia. Evaluation of their toxicity on Endothelial cells. Chem Mater. 2010;22:5420-5429.

19. Ding M, Kisin ER, Zhao J, et al. Size-dependent effects of tungsten carbide-cobalt particles on oxygen radical production and activation of cell signaling pathways in murine epidermal cells. Toxicol Appl Pharmacol. 2009;241:260-268.

20. Cornell RM, Schwertmann U. The iron oxides: structures, properties, reactions, occurrence and uses. New York: VHC; 1996.
International Journal of Nanomedicine

\section{Publish your work in this journal}

The International Journal of Nanomedicine is an international, peerreviewed journal focusing on the application of nanotechnology in diagnostics, therapeutics, and drug delivery systems throughout the biomedical field. This journal is indexed on PubMed Central, MedLine, CAS, SciSearch $\AA$, Current Contents ${ } /$ Clinical Medicine,

\section{Dovepress}

Journal Citation Reports/Science Edition, EMBase, Scopus and the Elsevier Bibliographic databases. The manuscript management system is completely online and includes a very quick and fair peer-review system, which is all easy to use. Visit http://www.dovepress.com/ testimonials.php to read real quotes from published authors. 